\title{
Comparison of different water-miscible solvents for the preparation of plasma and urine samples in metabolic profiling studies
}

\author{
Muhammed Alzweiri ${ }^{\mathrm{a}, *}$, David G. Watson ${ }^{\mathrm{a}}$, Chris Robertson $^{\mathrm{b}}$, \\ Graeme J. Sills ${ }^{\mathrm{c}}$, John A. Parkinson ${ }^{\mathrm{d}}$ \\ ${ }^{a}$ Strathclyde Institute for Pharmaceutical and Biomedical Sciences, Strathclyde University, 27 Taylor Street, Glasgow G4 ONR, United Kingdom \\ ${ }^{\mathrm{b}}$ Department of Statistics and Modelling Science, University of Strathclyde, 26 Richmond Street, Glasgow G1 1XH, United Kingdom \\ ${ }^{\mathrm{c}}$ Epilepsy Research Unit, University Division of Cardiovascular and Medical Sciences, Western Infirmary, Glasgow G11 6NT, United Kingdom \\ ${ }^{\mathrm{d}}$ WestCHEM, Department of Pure and Applied Chemistry, University of Strathclyde, 295 Cathedral Street, Glasgow G1 1XL, United Kingdom
}

\begin{abstract}
The Lowry method and a capillary electrophoresis method were used to analyse protein residues in the supernatant after solvent deproteination of plasma. Acetonitrile and acetone were much more effective than methanol and ethanol at reducing the levels of proteins in plasma. The ability of different solvents to decrease levels of phospholipids in plasma samples was assessed using electrospray ionisation mass spectrometry (MS). Phospholipid signals can obscure differences between samples in general metabolite profiling (i.e. non-target compound) studies. Acetonitrile was much more effective than methanol in reducing the MS signal due to phospholipids in plasma which is a consequence of the poor solubility of phospholipids in acetonitrile. The capability of the solvents at reducing salts in urine samples was also studied by using an amperometric method. Using this approach little difference was detected between methanol, ethanol, acetonitrile and acetone in their ability to desalt urine samples.
\end{abstract}

Keywords: Deproteination; Phospholipids; Capillary electrophoresis; Desalting; LC-MS; Profiling studies; Metabonomics

\section{Introduction}

The analysis of biological samples using liquid chromatography coupled with mass spectroscopy detection (LC-MS), in particular for metabolite profiling studies, requires proteinfree and/or salt-reduced preparations [1,2]. Metabonomics is an example of profiling studies concerned with finding the variability in metabolites among a collection of biological samples, followed by classification of the samples according to any revealed variability. Besides ultrafiltration and solid phase extraction, which are expensive and low-recovery deproteination procedures [3], precipitation of proteins from serum or plasma samples can be carried out by adding salts, some acids or water-miscible organic solvents [3-9]. Although all of these procedures can be used in discarding proteins prior to analysis by nuclear magnetic resonance (NMR) spectroscopy, addition of water-miscible organic solvent might be the best method prior to liquid chromatography mass spectrometry because it decreases electrolytes instead of increasing them. This should improve the MS sensitivity and avoid instrument capillary blockage. In addition, solvent deproteination has the advantage of better analyte recovery over the other methods [3,4]. In case of urine samples, some researchers prefer to reduce the salt in samples by further diluting them with water or with any water-miscible solvent [10].

In addition to removing proteins and salts from biological samples, we have found during our metabonomic studies that it is also often essential to remove phospholipids or to reduce their original concentrations because their strong signals may obscure other more important biomarkers and they tend to appear as background peaks throughout the chromatogram. In addition, they lack the reproducible responses required in MS analysis [11]. They might be consequently considered as false biomarkers by the statistical tools used for calculating the variability among biological samples as part of profiling studies. Added to this the phospholipids' ionic character can lead to further ion suppression during mass spectroscopy (MS) analysis [12]. 
In order to assess the effect of the solvent on the biological sample composition, four semipolar solvents were used in this study, namely: methanol, ethanol, acetone and acetonitrile. A number of publications have mentioned comparing studies of analyte recovery using different semipolar solvents, but little data are reported on the evaluation of solvents for removing undesirable biological molecules before introducing samples into the LC-MS systems.

The Lowry test, a colorimetric protein-general test was used to measure all types of protein remaining in the sample liquor after discarding the majority of the proteins [13-16]. Capillary electrophoresis (CE) can be used to carry out more specific protein analysis [17-21] and in the current work was able to resolve the albumin peak as a major protein from the other proteins in the deproteinated plasma samples. However, the semipolar solvents precipitated certain amounts of salts from the urine samples; the remaining salts in the sample supernatant would be expected to govern the electrical current properties of the final preparation after subtracting the blank contribution. Integrated mode pulse amperometry was chosen to measure the amount of salt remained in the samples because it is possible to hold the integration period of the current induced by salts at a constant potential for a certain time period during the pulse [22]. Then the waveform finishes with a reductive potential in order to clean away any oxides accumulated over the gold electrode during the course of the measurements [23,24]. Additionally, the integrated mode of detection provides a compensatory mechanism for any likely aging of the electrode during the analysis period [23]. Finally, Soya lecithin, which is a common phospholipid standard material [25-28] was mixed with a constant volume of each semipolar solvent under controlled conditions, in order to measure the solubility of lecithin in each solvent. The weight difference between the undissolved lecithin before and after the experiment was utilized to measure phospholipids' solubility in each solvent. The results are also supported by a mass spectrometry infusion study.

In this work, common water-miscible solvents were compared according to their ability in removing proteins, salts and phospholipids from the plasma and urine. Protein removal from plasma samples was analysed by using the Lowry method and a capillary electrophoresis (CE) method. The urine desalting ability of the solvents was evaluated by an integrated pulse amperometry technique. Finally, gravimetric analysis and direct infusion into the mass spectrometer were used in evaluating the remaining phospholipid content in the samples.

\section{Experimental}

\subsection{Chemicals and materials}

Methanol, acetonitrile, formic acid (98\%) and water of HPLC grade were purchased from VWR International Ltd. (Lutterworth, UK). Acetone, absolute ethanol and sodium hydroxide pellets were purchased from Riedel-deHaën (Germany). Hexadimethrine bromide (polybrene), ammonium formate $97 \%$, bovine serum albumin, copper(II) sulphate hydrate, FolinCiocalteu's phenol reagent $2 \mathrm{~N}$, potassium sodium $(+)$-tartarate,
1- $\alpha$-phosphatidyl choline (1- $\alpha$-Lecithin) Type IV-S from soyabean, sodium chloride and sodium carbonate were purchased from Sigma-Aldrich (Poole, UK). Syringe filters $4 \mathrm{~mm}$ in diameter with $0.45 \mu \mathrm{m}$ pore size, a PVDF membrane and a polypropylene housing having only $0.125 \mathrm{~cm}^{2}$ surface area were purchased from Whatman International Ltd. (England). Polyvar Microscope (Leica, Germany) was used to examine the precipitate under bright field light. Pictures were taken by the colour video digital camera JVC TK-12080E (JVC, Japan).

Blank plasma samples were obtained from the blood bank at Gartnavel General Hospital (Glasgow, UK), and stored at $-20^{\circ} \mathrm{C}$ prior to use.

\subsection{Capillary electrophoresis (CE) and Lowry test}

A HP 3D CE capillary electrophoresis unit was used with Chemstation ${ }^{\circledR}$ software version 10.03 for data acquisition (Agilent Technologies, Waldbronn, Germany) equipped with a UV diode array detector. The UV detection was carried out at a wavelength of $206 \mathrm{~nm}$. The cell bandwidth was $4 \mathrm{~nm}$. The applied voltage was set at $12 \mathrm{kV}$, the separation was carried out under a negative polarity mode (i.e. from negative to positive), and injection was carried out hydrodynamically at $50 \mathrm{mbar}$ pressure for $3 \mathrm{~s}$. The column used was a bare fused silica capillary (Polymicro Technologies, Phoenix, AZ, USA) having an internal diameter of $50 \mu \mathrm{m}$, a total length of $33.5 \mathrm{~cm}$ and effective length of $25 \mathrm{~cm}$. The temperature of the column was kept constant at $25^{\circ} \mathrm{C}$ during the analysis period. Prior to analysis, the column was flushed for 10 min with a $0.25 \mathrm{M} \mathrm{NaOH}$ solution followed by a $10 \mathrm{~min}$ flush with ammonium formate buffer ( $25 \mathrm{mM}$, pH 3.5). Finally the column was flushed for $15 \mathrm{~min}$ with polybrene, a polycationic polymer $(1 \%$, w/v solution), for coating the silica surface, followed by a final flush with ammonium formate buffer $(25 \mathrm{mM}, \mathrm{pH} 3.5)$ for $10 \mathrm{~min}$. The Lowry test was carried out according to its original reference [29].

\subsection{Sample preparation for analysis by capillary electrophoresis $(C E)$}

Plasma $(0.3 \mathrm{ml})$ was vortexed in a $1.5 \mathrm{ml}$ eppendorf tube with the same volume as one of the water-miscible solvents. The samples were centrifuged for $10 \mathrm{~min}$ at room temperature and $7000 \mathrm{rpm}$. Following this $0.3 \mathrm{ml}$ from the supernatant was mixed with $0.7 \mathrm{ml}$ of distilled water. Exceptionally, the samples treated with either ethanol and methanol were further diluted 25 times with distilled water. Then they were filtered through $0.45 \mu \mathrm{m}$ syringe filters. Standard preparations were made by dissolving bovine serum albumin in distilled water to achieve the following concentrations: $0.8,0.16,0.032$ and $0.006 \mathrm{mg} / \mathrm{ml}$.

\subsection{Determination of phospholipid solubility}

The experiment was carried out in a Clifton water bath equipped with a shaking stage. The parameters were $25 \pm 1{ }^{\circ} \mathrm{C}$ and $300 \mathrm{St} / \mathrm{min}$. Twelve $5 \mathrm{ml}$ dried and screw-capped glass vials 
were weighed and labelled according to the samples' ID. $100 \mathrm{mg}$ of lecithin was added into each glass vial with $2 \mathrm{ml}$ of a watermiscible organic solvent, the capped vials were enveloped with parafilm sheets, and then the samples were immersed in a suitable rack into the water bath.

The samples were shaken for $30 \mathrm{~min}$, then removed from the water bath and their external surfaces wiped clean. Previously weighed filter caps (made in-house) were substituted with the original vial caps and the solutions were filtered with the aid of suction. Subsequently, the vials and caps were left under a fume hood overnight to guarantee drying to completion. Finally they were weighed to establish the weight of undissolved lecithin in each sample, which was then subtracted from the original weight in order to calculate the amount of phospholipid dissolved in $2 \mathrm{ml}$ of solvent.

The results of the solubility experiment were supported by analysing plasma samples using direct infusion mass spectrometry (LCQ, Finnigan Mat). The analysis was carried out by using electropray ionisation in the positive mode with a capillary temperature of $250^{\circ} \mathrm{C}$, sheath gas flow $40 \mathrm{ml} / \mathrm{min}$, zero auxiliary gas and scan range $(150-2000) \mathrm{m} / \mathrm{z}$. The infusion flow was $10 \mu \mathrm{l} / \mathrm{min}$. The data of 32 scans was averaged for each sample. Twelve plasma samples were prepared from the same plasma stock by adding $100 \mu \mathrm{l}$ into a $1.5 \mathrm{ml}$ eppendorf tube and then the same volumes of either acetonitrile or methanol were added into the sample tube. Then the contents was vortex centrifuged for $10 \mathrm{~min}$ at $7000 \mathrm{rpm}$. Following this $100 \mu \mathrm{l}$ of the supernatant was diluted to $1 \mathrm{ml}$ using either acetonitrile or methanol. Finally, the samples were filtered through $0.45 \mu \mathrm{m}$ syringe filters before infusion into the MS system. Lecithin reference solution was prepared by dissolving lecithin in methanol to a concentration of $1 \mu \mathrm{g} / \mathrm{ml}$.

\subsection{Comparison of salt content in the urine following addition of water-miscible organic solvents}

The urine samples were collected from source and kept in the freezer at $-20^{\circ} \mathrm{C}$ until use. The stock urine samples were thawed then centrifuged at $2{ }^{\circ} \mathrm{C}$ for $10 \mathrm{~min}$ and $4000 \mathrm{rpm}$ to remove suspended particles and salt agglomerates. The supernatants were taken up immediately, and then supernatants were kept on the bench for $15 \mathrm{~min}$ to equilibrate to room temperature. $0.5 \mathrm{ml}$ of the solvents was added to $0.5 \mathrm{ml}$ of each urine sample. Subsequently, each sample was vortex mixed and centrifuged for $10 \mathrm{~min}$ at $4000 \mathrm{rpm}$. Then $0.25 \mathrm{ml}$ of the resultant solution was diluted to a total volume of $25 \mathrm{ml}$ with HPLC grade water. For each solvent three samples were prepared.

Blank samples were also prepared according to the same procedure but $0.5 \mathrm{ml}$ of HPLC grade water was used instead of urine. An ED 50 electrochemical detector (Dionex, UK) equipped with a titanium-body amperometry cell with a gold working electrode and $\mathrm{Ag} / \mathrm{AgCl}$ reference electrode was used in integrated amperometry mode. The waveform was selected to apply a constant potential during the integration period and to end up with a reducing potential for cleaning the working electrode from the oxidised materials. To obtain the results as an area under the curve (AUC) for the detector signals, the detector was attached with a Spectra System P100 HPLC pump (Spectra-Physics) fitted with a $20 \mu$ l loop Rheodyne injector, and with a DP700 integrator (Fisons instruments). During the analysis, the pump flow rate was maintained at $1 \mathrm{ml} / \mathrm{min}$ of HPLC water. Standard solutions of sodium chloride in HPLC water with concentrations $0.2-10 \mathrm{mg} / 100 \mathrm{ml}$ were prepared.

\section{Results and discussion}

\subsection{Protein determination}

In the $\mathrm{CE}$ analysis the experimental parameters and conditions were selected carefully to prevent adsorption of large proteins like albumin onto the surface of the fused silica capillary. In order to accomplish this, polybrene, which is a $\mathrm{pH}$-independent cationic polymer, was used to coat the inner wall of the silica capillary, and the $\mathrm{pH}$ of the analysis buffer ensured that albumin, which has an isoelectric point of 4.9 [30], was positively charged during the analysis. Fig. 1 shows a good peak shape for both bovine serum albumin (BSA) in the standard preparation and human serum albumin (HSA) in some of the precipitated plasma test solutions. The BSA peak migrated slightly earlier than HSA due to some slight structural differences between the proteins. The humps preceding the albumin peak are interpreted as other proteins present in the plasma. The Lowry test, which is a general spectrophotometric protein test, was used to quantify total protein in the plasma samples. Although the plasma samples deproteinated by methanol and ethanol were 25 times more dilute than the samples treated by either acetone or acetonitrile, the albumin peaks were still larger in the case of both methanol and ethanol. Albumin is the main protein in the plasma [30] and it is clear from the electropherograms in Fig. 1 that acetonitrile and acetone are much stronger deproteinisers than methanol and

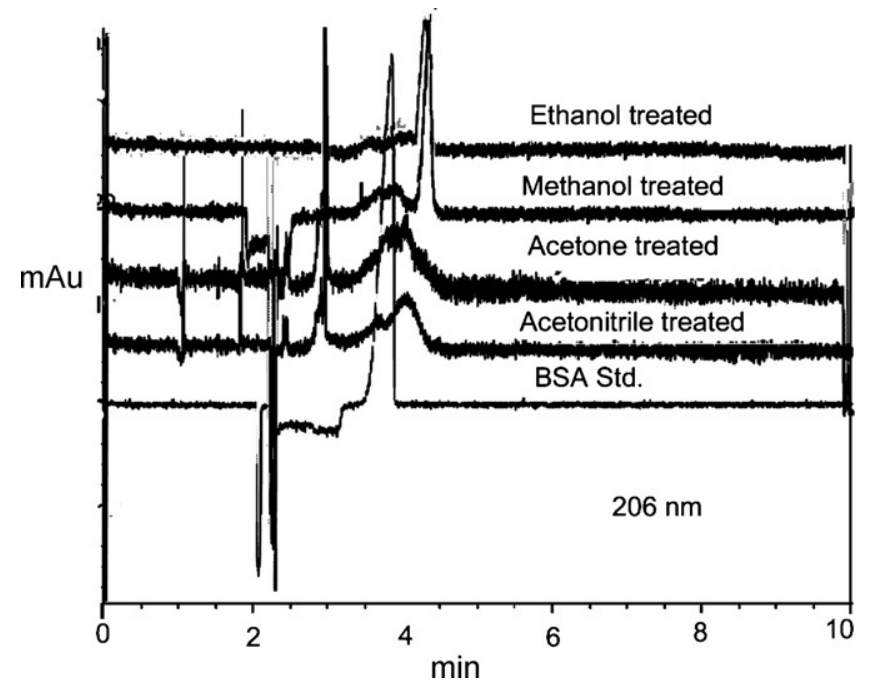

Fig. 1. Capillary electrophoresis traces showing the amount of HSA left in plasma following treatment with different water-miscible solvents in comparison with a BSA standard. 


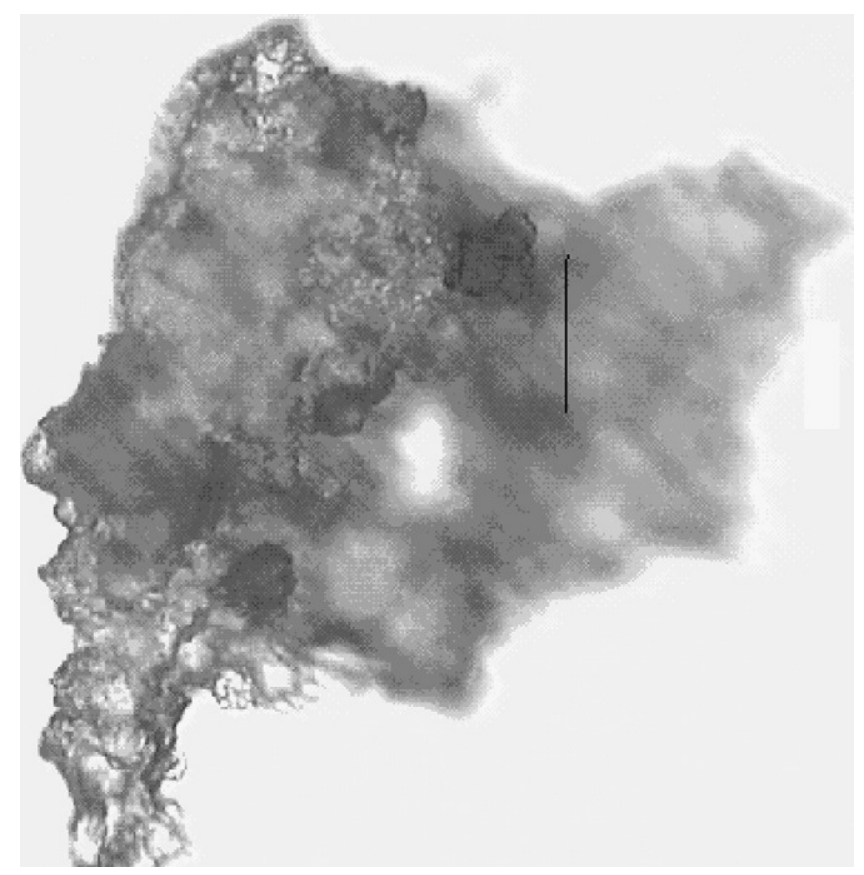

Fig. 2. Microscope picture of protein precipitated from plasma by acetonitrile (1:1). The precipitate forms an agglomerate.

ethanol. Acetonitrile and acetone have higher dielectric constant in comparison with methanol and ethanol [31] and lower viscosity. These two physical parameters control the association and dissociation forces between water and organic solvents on the one hand, and between proteins and solvent mixtures on the other. This will lead to different precipitation mechanisms for proteins according to the solvent used. Fig. 2 shows a microscopical image for a plasma sample treated with acetonitrile where the precipitation appears as a well-compacted mass, while methanol (Fig. 3) produces a precipitation like a fine suspension. The amount of albumin remaining in the sample supernatant after precipitating $1 \mathrm{ml}$ of plasma with $1 \mathrm{ml}$ of the solvent according to analysis by CE was $23 \mathrm{mg} / \mathrm{ml}$ for methanol and $18 \mathrm{mg} / \mathrm{ml}$ for ethanol, while the concentration was below the limit of detection $(6.4 \mu \mathrm{g} / \mathrm{ml})$ in the case of acetonitrile and acetone.

The Lowry test is widely used for protein analysis [32]. BSA Standard solutions showed good linearity within the range $25-200 \mu \mathrm{g} / \mathrm{ml}$. According to this test the amount of protein remaining in $1 \mathrm{ml}$ plasma supernatant, treated with the same volume of methanol, ethanol, acetone and acetonitrile, was cal-

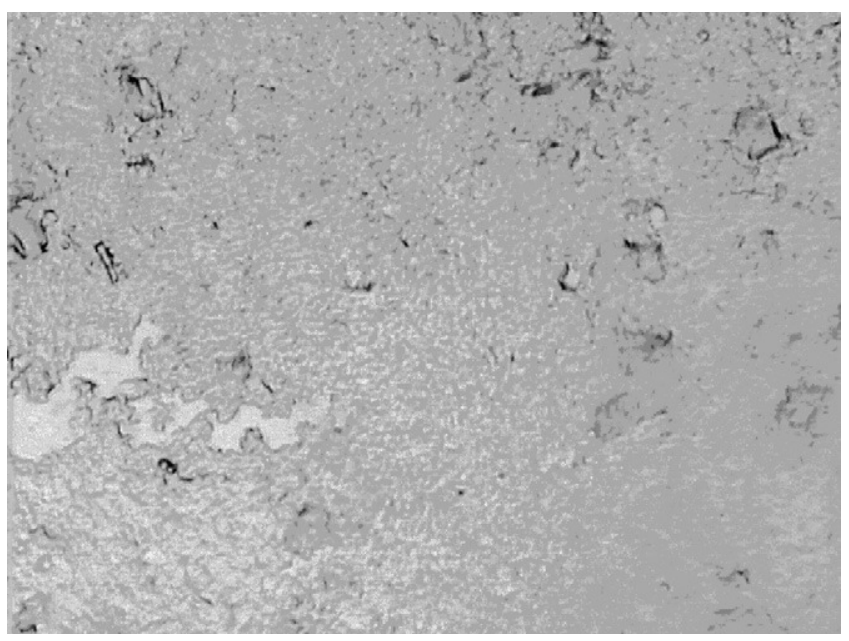

Fig. 3. Microscope picture of protein precipitated from plasma by methanol $(1: 1)$. The precipitate forms small particles.

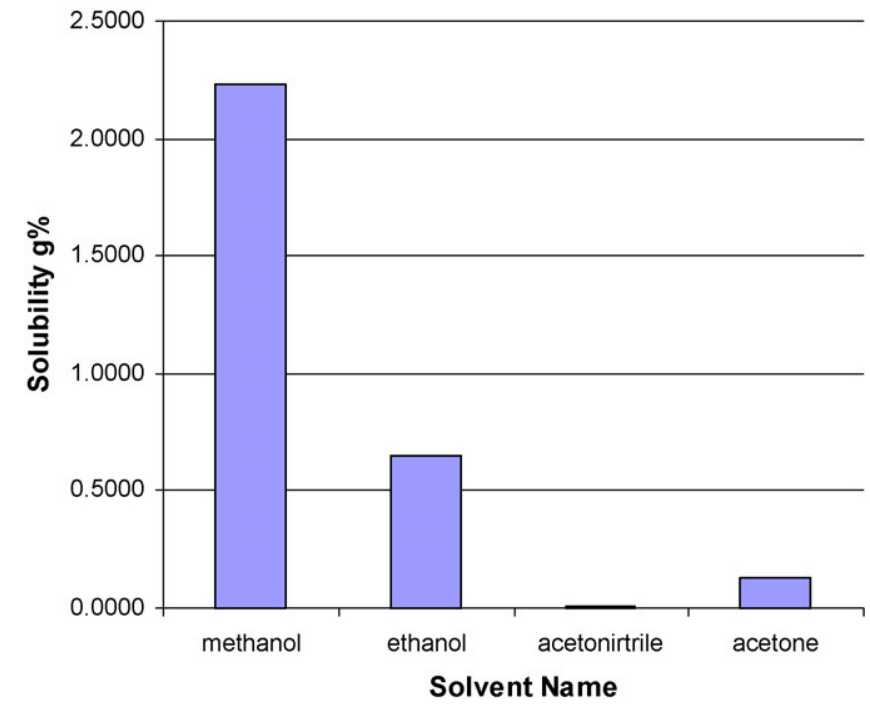

Fig. 4. Solubility of lecithin in four different water-miscible solvents.

culated to be $22.5,15.7,2.7$ and $2.25 \mathrm{mg} / \mathrm{ml}$, respectively. The results of this test are not far from those taken from the electrophoretic analysis. This is expected because the albumin is the dominant protein in plasma [3]. In conclusion, acetone and acetonitrile are much better than methanol and ethanol for protein elimination from plasma samples.

Total intensities of masses from mass-response tables

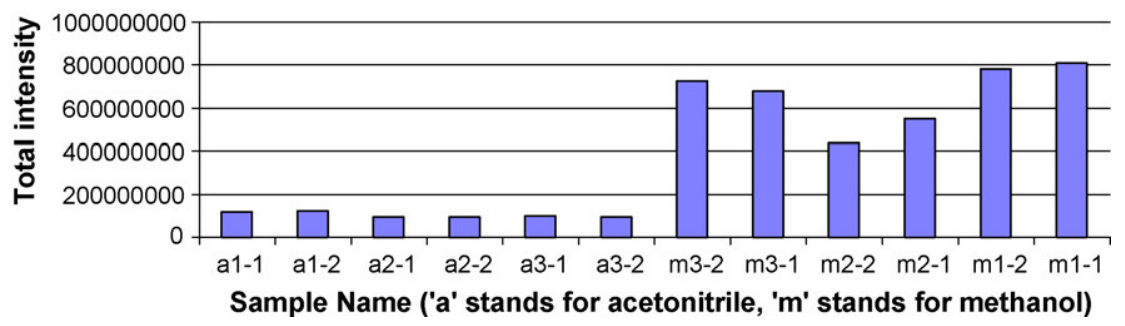

Fig. 5. Comparison of phospholipid mass spectral intensity for plasma samples treated with acetonitrile or with methanol. 


\subsection{Phospholipid determination}

Lecithin, which is used as a standard for the analysis of phospholipids, is a complex mixture [25]. Its components lack a distinct chromophore. Thus gravimetry was chosen as a method for assessing phospholipid solubility in the water-miscible solvents. This solubility experiment was designed to make sure that the sample vials and their caps were weighed at the beginning and at the end of the experiment in order to subtract their weights upon calculation of the amount of undissolved lecithin. The amount of lecithin dissolved in methanol, ethanol, acetone or acetonitrile was calculated by taking the difference of lecithin weight remaining in the samples after carrying out the solubility study and the original weight of lecithin in each sample. The results are shown in Fig. 4. The solubility of lecithin in methanol under the described conditions was $22.3 \mathrm{mg} / \mathrm{ml}$ and in acetonitrile was $0.12 \mathrm{mg} / \mathrm{ml}$. In order to confirm the results obtained on the solubility of phospholipids, plasma samples precipitated with either methanol or acetonitrile were infused into the mass spectrometer. The total intensity response plot for plasma samples (Fig. 5) shows that the plasma samples precipitated with methanol have much higher response for the phospholipid ions, which dominate in the total ion count (TIC) in comparison with those treated with acetonitrile. Moreover, it is shown in Fig. 6 that the vast majority of peaks in the infused plasma sample charts are related to phospholipids; lecithin standard solution showed four main peak clusters, around 500, 800, 1300 and $1600 \mathrm{~m} / \mathrm{z}$. The peaks around 500 and $800 \mathrm{~m} / \mathrm{z}$ are for phospholipid monomers and those around 1300 and $1600 \mathrm{~m} / z$ are due to hetero- and homodimers of the phospholipid molecules. The large peak clusters observed in plasma samples are located at the same mass ranges as those in the lecithin standard. Acetoni-
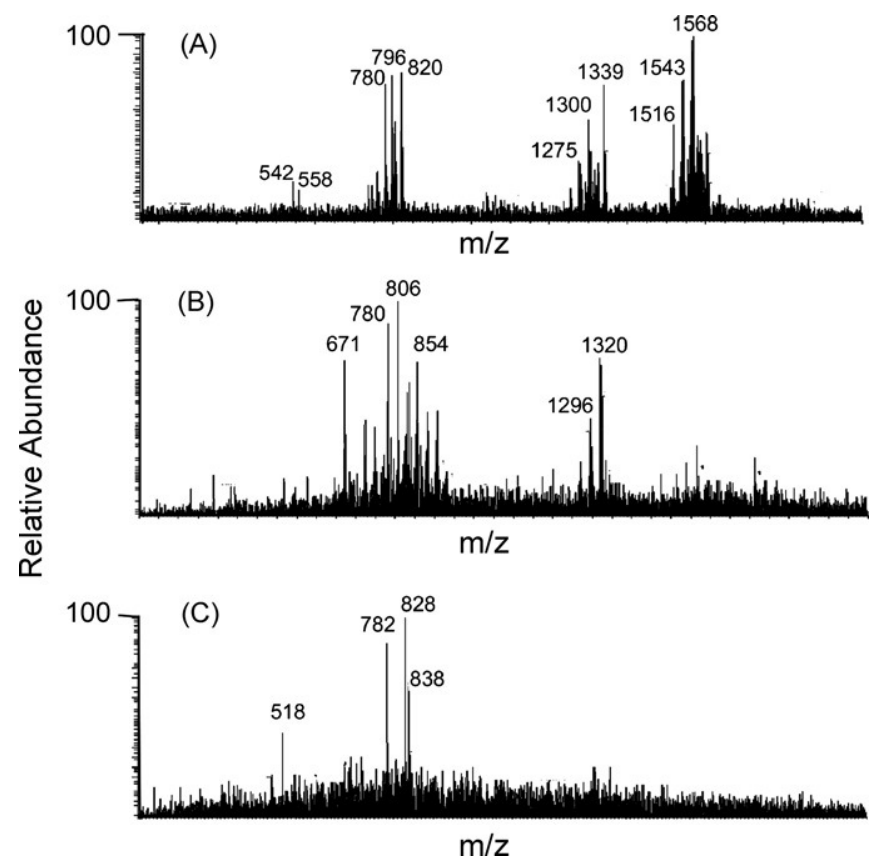

Fig. 6. Direct infusion mass spectra: (A) phospholipids in lecithin, (B) phospholipids in methanol treated plasma and (C) phospholipids in acetonitrile treated plasma.

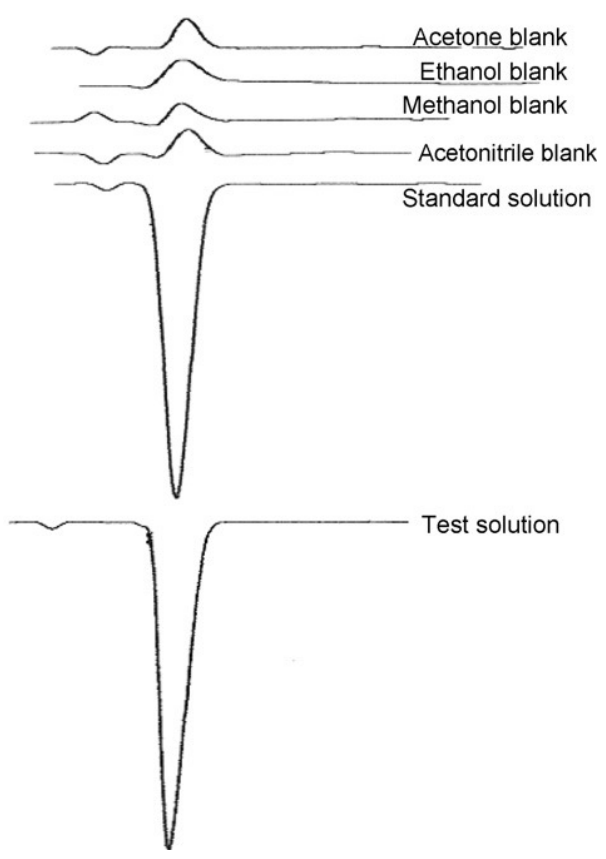

Fig. 7. Peaks obtained from urine samples treated with different organic solvents using an ED50 amperometric detector. Blank solutions have a small negative response, while the sample and the standard have clear positive peaks.

trile precipitated plasma has low responses in the region around 1300 and $1600 \mathrm{~m} / \mathrm{z}$. This might be explained by the fact that, acetonitrile has slightly higher dielectric constant and lower viscosity than methanol. This will improve droplet dispersion in the electrospray ionization (ESI) process [31] thus reducing cluster formation.

\subsection{Salt determination}

The ED50 detector was used to measure the amount of salt in the urine following treatment with one of the water-miscible solvents. The peak areas obtained (Fig. 7) were used to measure the salt content. Blank samples show small negative peaks participating in measurement error, which was not exceeding 5\%. The linearity between the concentration of salt and the response by using ten different concentrations of sodium chloride was linear in a narrow range $1-5 \mathrm{mg} \%$, so the test samples were diluted to have peak areas within this range. If the average response of acetone-desalted samples is assumed to be $100 \%$, then acetonitrile, methanol and ethanol possessed 101.3, 79.6 and 80.9\%, respectively. Thus methanol and ethanol show slightly higher desalting ability.

\section{References}

[1] H.C. Keun, Pharmacol. Ther. 109 (2006) 92.

[2] J.I. Castrillo, A. Hayes, S. Mohammed, S.J. Gaskell, S.G. Oliver, Phytochemistry 62 (2003) 929.

[3] C.A. Daykin, P.J.D. Foxall, S.C. Connor, J.C. Lindon, J.K. Nicholson, Anal. Biochem. 304 (2002) 220

[4] S. Souverain, S. Rudaz, J.L. Veuthey, J. Chromatogr. A 61 (2004) 1058.

[5] S. Souverain, S. Rudaz, J.L. Veuthey, J. Pharm. Biomed. Anal. 35 (2004) 913. 
[6] H. Jalalizadeh, E. Souri, M.B. Tehrani, A. Jahangiri, J. Chromatogr. B 854 (2007) 43.

[7] C. Georgita, F. Albu, V. David, A. Medvedovici, J. Chromatogr. B 854 (2007) 211

[8] M. Zhou, X. Chen, D. Zhong, J. Chromatogr. B 854 (2007) 219.

[9] C. Ekhart, A. Gebretensae, H. Rosing, S. Rodenhuis, J.H. Beijnen, A.D.R. Huitema, J. Chromatogr. B 854 (2007) 345.

[10] R. Plumb, J. Granger, C. Stumpf, I.D. Wilson, J.A. Evans, E.M. Lenz, Analyst 128 (2003) 819.

[11] M. Koivusalo, P. Haimi, L. Heikinheimo, R. Kostiainen, P. Somerharju, J. Lipid Res. 42 (2001) 663.

[12] J. Hayakawa, Y. Okabayashi, J. Pharm. Biomed. Anal. 35 (2004) 583.

[13] D.H. Beezhold, D.A. Kostyal, V.J. Tomazic-Jezic, Methods 27 (2002) 46.

[14] L.F. Capitan-Vallvey, O. Duque, G. Miron-Garcia, R. Checa-Moreno, Anal. Chim. Acta 433 (2001) 155.

[15] O.H. Lowry, N.R. Rosebrough, A.L. Farr, R.J. Randall, J. Biol. Chem. 193 (1951) 265.

[16] A.L. Winters, F.R. Minchin, Anal. Biochem. 346 (2005) 43.

[17] K.D. Altria, J. Pharm. Biomed. Anal. 31 (2003) 447.

[18] J.R. Catai, H.A. Tervahauta, G.J. de Jong, G.W. Somsen, J. Chromatogr. A 185 (2005) 1083.

[19] R.W. Chiu, J.C. Jimenez, C.A. Monnig, Anal. Chim. Acta 307 (1995) 193.
[20] A. Eckhardt, I. Miksik, Z. Deyl, J. Charvatova, J. Chromatogr. A 111 (2004) 1051.

[21] V. Sanz-Nebot, F. Benavente, E. Balaguer, J. Barbosa, Electrophoresis (2003) 883-891.

[22] J. Wang, Talanta 56 (2002) 223.

[23] K. Sato, J.-Y. Jin, T. Takeuchi, T. Miwa, K. Suenami, Y. Takekoshi, S. Kanno, J. Chromatogr. A 919 (2001) 313.

[24] J.-W. Lee, I.-H. Yeo, Microchemi. J. 70 (2001) 173.

[25] M.O. Taha, H. Abdel-Halim, M. Al-Ghazawi, E. Khalil, Int. J. Pharm. 295 (2005) 135.

[26] R. Szucs, K. Verleysen, G.S.M.J.E. Duchateau, P. Sandra, B.G.M. Vandeginste, J. Chromatogr. A 738 (1996) 25.

[27] M. Sznitowska, E.A. Dabrowska, S. Janicki, Int. J. Pharm. 246 (2002) 203

[28] H. Bunjes, M.H.J. Koch, J. Control. Rel. 107 (2005) 229.

[29] O. Lowry, N. Rosebrough, L. Farr, R. Randall, J. Biol. Chem. 193 (1951) 265-275.

[30] C.Z. Huang, W. Lu, Y.F. Li, Y.M. Huang, Anal. Chim. Acta 556 (2006) 469.

[31] L. Charles, D. Pepin, F. Gonnet, J.C. Tabet, J. Am. Soc. Mass Spectrom. 12 (2001) 1077.

[32] R. Kumar, A.K. Shukla, E. Bagga, S. Kumari, R.P. Bajpai, L.M. Bharadwaj, Anal. Biochem. 336 (2005) 132. 